\title{
Menire bij'ôk: uma cerimônia de mulheres Mẽbêngôkre
}

\author{
Dilma Costa Ferreira ${ }^{1}$ \\ Universidade Federal do Pará \\ Irerwyk Kayapó ${ }^{2}$ \\ Universidade Estadual do Pará
}

Resumo: Este trabalho é produto de uma atuação conjunta entre pesquisadora não indígena e pesquisador indígena. Reflete sobre experiências em torno da produção de pessoa, confecção de artefatos cerimoniais, enfatizado as riquezas culturais e materiais do povo Mẽbêngôkre. Para tanto, traz à baila um relato etnográfico da cerimônia Menire Bij'ôk - as mulheres pintadas. Discorre sobre os rituais de passagem e de nominação que ocorrem no final das cerimônias como Bemp, Kwywykangô, Menire Bij’ôk e Memy Bij’ôk. Porém, vale ressaltar que há outras cerimônias próprias para dar nomes, geralmente de curta duração, como Panhte, Kokô e Ngrere. A fim de fundamentar essa pesquisa, além de produção colaborativa com pesquisador indígena, de documentação de relato etnográfico da cerimônia Menire Bij'ôk, praticada por mulheres. Foram realizadas entrevistas, com dois colaboradores Mẽbêngôkre. Construindo uma abordagem na qual se analisa eventuais mudanças ou transformações ocorridas na realização de tais cerimônias no tempo e no espaço, levando em consideração a dinamicidade da "cultura".

Palavras-Chave: Cerimônias; Mẽbêngôkre; Parentesco; Nominação.

\footnotetext{
1 Mestranda pelo Programa de Pós-graduação em Antropologia PPGA/UFPA. Especialista em Psicopedagogia Educacional. Graduada com Licenciatura em pedagogia. E-mail: dilma1992cf@gmail.com.

2 Graduado Licenciatura intercultural indígena pela Universidade Estadual do Pará, UEPA. Professor Indígena, pertencente a etnia Mebengôkre, da aldeia Kremajti, município de São Félix do Xingu/PA. E-mail: irerwyk123@gmail.com.
} 


\title{
Menire bij'ôk: a women's ceremony Mẽbêngôkre
}

\begin{abstract}
This work is the product of a joint action between a non-indigenous researcher and an indigenous researcher. It reflects on experiences around the production of person, making of ceremonial artifacts, emphasizing the cultural and material riches of the Mẽbêngôkre people. To do so, it brings to light an ethnographic account of the ceremony Menire Bij'ôk - women painted. It discusses the rituals of passage and nomination that occur at the end of ceremonies such as Bemp, Kwywykangô, Menire Bij'ôk and Memy Bij'ôk. However, it is worth mentioning that there are other ceremonies proper to give names, usually of short duration, like Panhte, Kokô and Ngrere. In order to base this research, as well as a collaborative production with an indigenous researcher, of documentation of ethnographic reporting of the ceremony Menire Bij'ôk, practiced by women. Interviews were conducted with two Mẽbêngôkre collaborators. Constructing an approach which analyzes possible changes or transformations in the realization of such ceremonies in time and space, taking into account the dynamics of "culture".
\end{abstract}

Keywords: Ceremonies; Mẽbêngôkre; Kinship; Nomination.

\section{Menire bij'ôk: una ceremonia de mujeres Mẽbêngôkre}

\begin{abstract}
Resumen: Este documento es el producto de una acción conjunta entre el investigador investigador no indígena y indígena. Reflexiona sobre experiencias en torno a la persona de la producción, la producción de artefactos ceremoniales, destacó la riqueza cultural y material de las personas Mebengokré. Por lo tanto, nos lleva a una cuenta etnográfico de Menire Bij'ôk ceremonia - las mujeres pintadas. Discute los ritos de paso y nominación que se producen al final de las ceremonias como BEMP, Kwywykangô, Menire Bij'ôk y Memy Bij'ôk. Sin embargo, cabe destacar que hay otras ceremonias a sí mismos a nombre, por lo general de corta duración, como Panhte, Koko y Ngrere. Para apoyar esta investigación y producción en colaboración con el investigador indígena de descripción etnográfica de la documentación ceremonia Menire Bij'ôk practicada por las mujeres. Las entrevistas se realizaron con dos empleados Mebengokré. La construcción de un enfoque que analiza los cambios o transformaciones en la realización de este tipo de ceremonias en el tiempo y el espacio, teniendo en cuenta la dinámica de la "cultura".
\end{abstract}

Palabras clave: Ceremonias; Mebengokré; Parentesco; Nominación. 


\title{
Introdução
}

$\mathrm{P}$ ara início de conversa, enfatizamos que esta abordagem das cerimônias Mẽbêngôkre e, especialmente o relato etnográfico de Menire Bij’ôk, é uma produção colaborativa entre o pesquisador e professor indígena Irerwyk, residente na aldeia Kremajti, município de São Félix do Xingu, PA, e eu, também pesquisadora e professora com experiência docente em escolas indígenas Mẽbêngôkre por um período de quatro anos. O trabalho conta ainda com os colaboradores Bepdjà e Pàtkore, igualmente pesquisadores e professores indígenas.

Na gestão de uma cerimônia ocorre um longo processo. Podemos afirmar que há ritual em praticamente tudo. Na escolha da pintura, dos acessórios, das cores e tamanhos de miçangas que irão compor os adornos, corte de cabelo, comidas, local e convites a serem expedidos. Tudo isso compõe o início de uma cerimônia. Por essa razão, normalmente a duração de um evento como esse pode chegar a meses. Isso não significa que haverá dança em todo o decorrer cerimonial. As danças, geralmente acontecem quando se caminha para o grande final, a metoro raj (grande dança).

André Demarchi (2016: 109) relata que:

\begin{abstract}
são as mulheres que decidem, nos momentos que precedem os grandes rituais, quais as cores e formas que serão combinadas nos enfeites de miçangas de uso comum, utilizados por todos os participantes. Esta escolha está relacionada ao motivo de pintura corporal que os diferentes grupos de gênero e idade portarão durante o ritual. As mulheres procuram formas e cores que combinam com os grafismos geométricos feitos com tintas pretas e vermelhas (respectivamente, a base de jenipapo e ururcu) pintados nos diferentes corpos dos participantes. Tal decisão é permeada por divisões em grupos de idade e gênero. As mulheres mais velhas, que já possuem filhos e netos, decidem entre si, quais serão os seus enfeites e os de seus maridos. O mesmo acontece com o grupo de mulheres da geração precedente que, em geral, possuem apenas filhos e não netos. As mekurerere, as moças púberes, encarregam-se de escolherem as formas e cores de seus colares e dos menoronyre, os rapazes solteiros da aldeia.
\end{abstract}

\section{Ainda segundo André Demarchi (2016: 110):}

As conversas sobre os enfeites podem acontecer quando as mulheres, novamente divididas em grupos de idade, se reúnem para pintarem-se entre si em longas sessões coletivas de pintura corporal. Podem acontecer quando as mulheres vão às roças ou quando vão buscar lenhas para seus fornos de pedra, ou mesmo, nos animados banhos de rio ao pôr do sol (...).

As cerimônias dispõem de rituais importantes, são nelas que ocorrem os ritos de passagem e de nominação. Os nomes são dados geralmente para crianças, os tàpdjwy (netos ou sobrinhos). Esse ritual acontece no final das cerimônias e constitui um ato "oficial" de dar nomes às pessoas. Contudo os nomes não são dados de forma aleatória. Existem cerimônias onde só homens podem receber nomes, outras em que os dois, tanto homens quanto mulheres recebem nomes, e há aquelas em que são dados nomes apenas para as mulheres.

Além disso, se destaca ainda o critério de raiz de nomes, que são próprios de cada cerimônia. O Bemp é exemplo de uma cerimônia em que apenas os homens ganham nomes que serão iniciados com a raiz Bep. Existe ainda o rito cerimonial denominado Tàkàk, nele tanto homem, quanto mulher recebe 
nomes. Aos homens são conferidos nomes que iniciam com a raiz Tàkàk, e às mulheres são dados nomes de raiz Nhàk.

Atualmente há duas cerimônias que raramente acontecem, o Panthe e a Kôkô. No Panhte são dados nomes às mulheres cuja raiz inicia-se com Panh ou Panhte. No rito Kôkô, são conferidos nomes a mulheres e em alguns casos aos homens também, os quais se iniciam com Kôkô.

Outras cerimônias também possuem esse ritual de nominação, temos a Menire Bij'ôk em que participam apenas mulheres e são conferidos nomes com raiz Bekwynh, geralmente usado por mulheres. Mas, é possível encontrar nomes masculinos que iniciam com essa raiz nominal.

Vale ressaltar que existem raízes de nomes que são conferidos em outras cerimônias e, em alguns casos, há aqueles que possuem um nome, mas não foi "oficializado" em nenhum rito cerimonial ou não é um "nome bonito", como denomina a antropóloga Vanessa Lea (2012). Talvez isso se deva ao fato de que as cerimônias atualmente não ocorrem mais com tanta frequência e os pais têm de esperar um pouco mais para que sejam dados aos filhos, nomes oficiais.

Segundo relatos dos colaboradores deste trabalho3, Bepdjà Kayapó e Pàtkôre Kayapó, em relação a dinâmica cultural vivenciada nas aldeias Mẽbêngôkre, sobretudo no que diz respeito aos ritos cerimoniais, foi possível perceber que noutros tempos as cerimônias seguiam uma sequência, sendo estas uma forma de marcar o tempo, as estações do ano, caracterizados como estações secas (ngô ngrà) ou estações chuvosas (ngô tàm), mais ou menos o que chamaríamos de inverno e verão, porém com significações inerentes à uma cosmovisão que se diferencia da concepção ocidental. As fases da lua também possuíam um papel importante nessa contagem.

No que tange a dinamicidade da "cultura", Marshall Sahlins (1997: 41), em debate sobre o uso do termo aplicado as sociedades indígenas, sugere que esta, "não pode ser abandonada, sob pena de deixarmos de compreender o fenômeno único que ela nomeia e distingue: a organização da experiência e da ação humana por meios simbólicos".

Manuela Carneiro da Cunha (2017: 307) reitera

\begin{abstract}
Enquanto a antropologia contemporânea, como Marshall Sahlins apontou, vem procurando se desfazer da noção de cultura, por politicamente incorreta (e deixá-la aos cuidados dos estudos culturais), vários povos estão mais do que nunca celebrando sua "cultura" e utilizando-a com sucesso para obter reparações por danos políticos. A política acadêmica e a política étnica caminham em direções contrárias. Mas a academia não pode ignorar que a "cultura" está ressurgindo para assombrar a teoria ocidental.
\end{abstract}

Há algumas décadas, as cerimônias mantinham uma estreita ligação com a natureza, porém nos dias atuais, nota-se uma nova forma de organização desses ritos cerimoniais. $O$ primeiro fator que tipifica essa dinâmica pode ser observado pelo fato de não serem mais realizadas com tanta frequência, não seguem à risca esse caráter determinado pelo tempo, estações secas ou chuvosas, fases da lua, etc., como ocorria.

Diante do exposto, cabe trazer para reflexão as considerações de Sahlins (1997: 41), de que "Essa ordenação (e desordenação) do mundo em termos simbólicos, essa cultura é a capacidade singular da espécie humana”. Nesse

${ }_{3}$ Colaborador 1: Bepdjá Kayapo, residente na aldeia Mojkarakô, localizada no município de São Félix do Xingu-PA, as margens do Riozinho, professor indígena e aluno do curso Intercultural Indígena pela UEPA. Colaborador 2: Pàtkôre Kayapo, residente na aldeia Kawatire, localizada no município de São Félix do Xingu-PA, as margens do rio Xingu, professor indígena e aluno do curso Intercultural Indígena pela UEPA. 
sentido, é perfeitamente compreensível essa reorganização ou dinâmica cultural a que estão sujeitos povos indígenas e populações tradicionais.

Demarchi (2015) chama atenção para as diferentes programações ocorridas entre os Mẽbêngôkre na atualidade, como festa do dia do índio na cidade, comemoração do dia da Independência, aniversário da aldeia, recepção de político na aldeia, dentre outras. Não negamos que há uma preparação ritualística para participação nessas programações, assim como em qualquer atividade desenvolvida entre os Mẽbêngôkre.

Como afirma o pesquisador, André Demarchi (2015: 110) referindo-se aos Mẽbêngôkre e cotidiano da aldeia Môjkarakô:

\begin{abstract}
Para os Mẽbêngôkre, a separação, mesmo que analítica, entre cotidiano e ritual parece não render muito, pois grande parte das atividades, ditas cotidianas, estão inseridas no longo processo de produção ritual, entendido aqui como momento ápice de produção de beleza. Assim, por exemplo, a produção de enfeites de miçangas, as sessões quinzenais de pintura corporal, as inúmeras expedições de coleta de jenipapo e casca de árvore para produzir a tinta que cobre os corpos, a coleta de lenha na floresta, a limpeza da do pátio da aldeia e da pista de pouso, sem falar nas expedições de caça e pesca e a produção de alimentos, - todas essas atividades presenciadas no cotidiano de Môjkarakô possui um forte vínculo com a diversificada produção de cerimônias e algumas delas são extremamente ritualizadas.
\end{abstract}

De fato, a vida em uma comunidade Mẽbêngôkre se concretiza em preparação ritualística constante. Os corpos e artefatos estão sendo incessantemente produzidos. Mas, quando nos referimos a cerimônias, nesse trabalho, voltamo-nos para as cerimônias tidas como tradicionais, gestadas dentro de uma cosmovisão ancestral, ritualística, que se encontram referenciadas, inclusive em narrativas históricas e míticas. Naturalmente, estas vem sofrendo mudanças, devido a dinâmica cultural envolta aos povos indígenas.

Quanto às comidas tradicionais, já não é servido somente comidas típicas de cada cerimônia, mas outros alimentos também estão sendo introduzidos. Em Menire Bij'ôk, por exemplo, a principais alimentações eram carne de jabuti e berarubu. Mas atualmente há a introdução de comidas industrializadas, oriundas da sociedade ocidental, como pijdjô kangô (refrigerante), djôpoj (bolachas) e outros.

Para aquisição desses alimentos é necessário dinheiro ou patrocínio, o que demanda tempo. Essa mudança em hábitos culturais, conforme relatado pelos colaboradores Pàtkôre da aldeia Kawatire e Bepdjà da aldeia Mojkarakô, pode influenciar inclusive na determinação do dia em que a cerimônia irá iniciar. Sobretudo por razões econômicas, e assim não terem condições de comprar comidas para dar início a alguma cerimônia outrora prevista. Mas, se percebermos a cultura dos povos indígenas em termos simbólicos, a apropriação desses alimentos ocidentais pode significar a introdução de uma nova comida típica em cerimônias e rituais e até mesmo resultar em outros desdobramentos. Esta é uma hipótese a ser pesquisada em outro momento.

De acordo com Bepdjá Kayapó, professor indígena e morador da aldeia Mojkarakô, algumas cerimônias não ocorrem mais atualmente, como a festa do milho, que marcava o início das roças, a cerimônia do timbó - ritual para se pescar peixes, dentre outras. Há os que alegam ser apenas os mais velhos sabedores dos ritos, especialmente os pajés (wajanga), e estes não repassam esse conhecimento. Os mais velhos dizem justamente o contrário, que alguns jovens atualmente não apresentam interesse em aprender os saberes tradicionais do Povo. 
O pajé ou xamã é, ou era, como relata Terence Turner (1991), considerado um líder máximo na aldeia, aquele que cura, o homem que fala com os espíritos da natureza e as curas xamânicas eram feitas por vários meios. Além do tratamento com ervas e expulsão de espíritos que cercam uma pessoa doente e tentam roubar sua alma. Eles também praticavam magias para a agricultura e para a caça. Era ainda função dos xamãs nas guerras, localizar o inimigo e predizer seus movimentos, interpretar presságios, etc.

Mas, na visão de Turner (1991), as práticas xamânicas parecem ter entrado em declínio a partir dos anos 60 e 70 tendo em vista que estas eram mais requeridas quando surgia problemas de saúde e perigos de guerra, contudo nesse período, devido ao contato e dependência da medicina ocidental e o fim dos ataques de guerra, o xamanismo "perde" sua função. Porém, ressurge nos anos 80 com uma nova roupagem, combinando aspectos políticos e culturais. Daí temos grandes nomes como o de Raoni.

Vanessa Lea (2012:166) argumenta que atualmente, tem se apresentado

\begin{abstract}
O desinteresse dos jovens em aprender o oficio de pajé, muito embora, não sejam todas as pessoas que possam aprendê-lo, mas a quem se designa tal função, essa prática deve ser aprendida na mocidade, mas praticada apenas na velhice, pois os xamãs só podem receber tal título publicamente quando estão bem velhos.
\end{abstract}

O desinteresse em aprender questões relacionadas a cultura e inclusive o ofício de wajanga, (categoria nativa para nomear pessoa que habitualmente conhecemos por pajé ou xamã), pelos mais jovens, reside no "aumento da interação com o mundo dos kuben, que está corroendo a onisciência dos velhos e estes reclamam que os jovens não se interessam por aprender sua cultura tradicional" (LEA, 2012: 167).

Diante do exposto, é possível pensar em dinâmicas e ressignificações culturais, no que tange a cerimônias e rituais e mesmo na cosmovisão Mẽbêngôkre atual. Talvez devêssemos analisar as condições geográficas, climáticas, históricas e sociais a que estão submetidos os povos indígenas, que mesmo diante de situações desfavoráveis, de opressão e resistência, não deixam de lado suas práticas culturais. E, parece natural que os rituais acompanhem a dinâmica existente no meio.

Como sugere Sahlins (1997: 52);

\begin{abstract}
Portanto, devemos prestar alguma atenção aos hesitantes relatos etnográficos sobre povos indígenas que se recusavam tanto a desaparecer quanto a se tornar como nós. Pois acontece que essas sociedades não estavam simplesmente desaparecendo há um século atrás, no início da antropologia: elas ainda estão desaparecendo - e estarão sempre desaparecendo. O pequeno ritual de iniciação a que submetemos os estudantes do primeiro ano de pós-graduação em antropologia, exortando-os a viajar e estudar as sociedades exóticas enquanto elas ainda estão lá, repete-se anualmente há gerações. Pois ao menos aqueles povos que sobreviveram fisicamente ao assédio colonialista não estão fugindo à responsabilidade de elaborar culturalmente tudo o que lhes foi infligido. Eles vêm tentando incorporar o sistema mundial a uma ordem ainda mais abrangente: seu próprio sistema de mundo.
\end{abstract}

Destacamos, dentre as cerimônias que acontecem atualmente, Kwyrykangô, conhecida popularmente como a festa da mandioca. Nesta participam homens e mulheres. O Bemp, entendido por alguns não indígenas como o ritual do casamento e dura vários dias. As cerimônias Tàkàk, Kôkô e Panhte, embora aconteçam com menos frequência, são rituais exclusivos de nominação.

Porém há duas cerimônias que ocorrem com maior frequência. O Memy $B \dddot{j}$ 'ôk, a cerimônia dos homens pintados, exclusivamente para homens, e 
Menire Bijôk $k$, a cerimônia de mulheres pintadas, um rito cerimonial para mulheres, sendo a única em que há apenas a presença feminina.

Conforme Vanessa Lea (1994: 93 - 94) em artigo que analisa a questão do gênero entre os Mẽbêngôkre, há uma certa complexidade existente na cerimônia Memy Bij'ôk, dos homens, em relação a cerimônia Menire Bij'ôk, das mulheres. Os Mebengôkre afirmam que há mais "cultura" (kukràdzë), ou seja, as partes que
constituem o todo, na cerimônia masculina do que na feminina. [...] A versão
masculina também é mais cara; exige uma quantidade maior de alimentos, sendo
desempenhada com maior vigor. Este exemplo mostra como se pode, a partir da
biologia, tecer representações sobre gênero até no conteúdo e no desempenho das
cerimônias.

Abaixo, traremos um relato etnográfico da cerimônia Menire Bij’ôk. O objetivo é propiciar melhor entendimento de tais ritos cerimoniais e sua relevância cultural, embora muito do que foi descrito esteja sofrendo mudanças. Isso se dá justamente pela dinamicidade cultural evolvente entre os povos indígenas. A escolha por uma cerimônia exclusiva para mulheres foi proposital, sobretudo por ser a única conhecida com esse fim.

\section{Menire Bij’ôk}

A cerimônia Menire Bijôk - mulheres pintadas, como indica o nome, é uma cerimônia na qual participam apenas mulheres, mekurerere - adolescentes que ainda não tiveram filhos; mebengêt - mulheres idosas, geralmente se usa esse termo para indicar uma mulher que já tem netos; mekrapdire - termo utilizado para designar mulheres que já tiveram filhos, embora algumas ainda sejam bastante jovens. Todas participam da cerimônia. É uma cerimônia que acontece em vários dias e chega há quatro meses mais ou menos. As mulheres se sentam em círculo no meio da aldeia e começam a entoar cantos ${ }^{4}$ (mengrére), sinalizando o início da cerimônia.

A seguir, imagem de mulheres reunidas no início da cerimônia Menire Bij'ôk em abril de 2013, na aldeia Kikretum, localizada a margem direita do Rio Fresco. Estão reunidas mulheres da aldeia Kikretum e Apexti (também localizada a margem do Rio Fresco). 


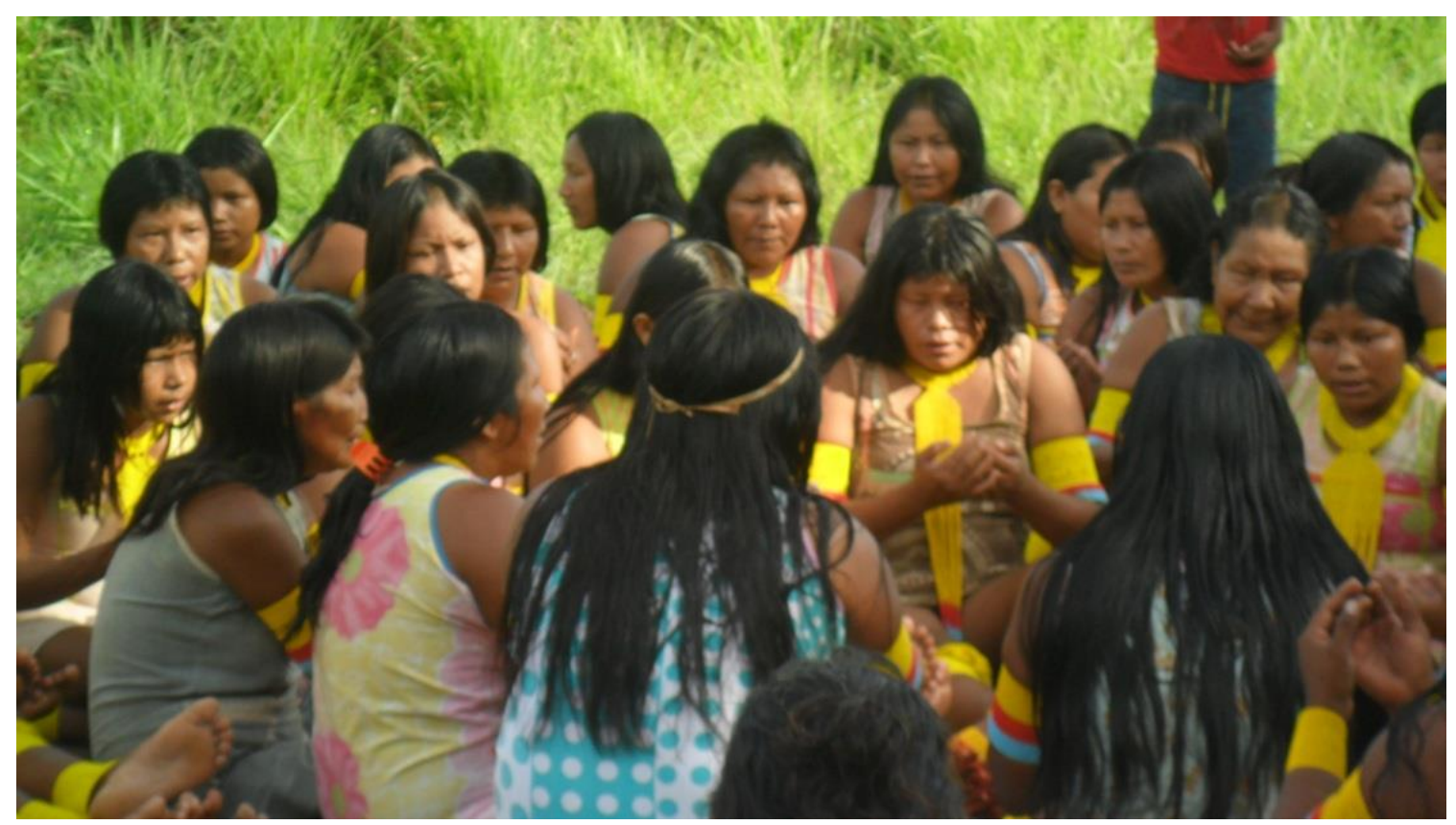

Figura 1 - Mulheres reunidas em início da cerimônia Menire Bij’ôk. Aldeia Kikretum, 2013. (Foto: arquivo pessoal).

É de responsabilidade do dono da cerimônia, chamado de mekrareremex, a distribuição da comida em todos os dias. Nos primeiros dias são servidos peixe (Tep mrõ), djôkupu (berarubu) entre outras comidas. No total são três mekrareremex, todos homens, e as mulheres não têm participação na busca por alimentos.

A cerimônia é sempre feita em homenagem a uma pessoa escolhida pelo "dono da festa", e é marcada inicialmente por três $b \hat{o}^{6}$ que configuram três etapas iniciais. No primeiro bô temos a confecção do artefato pelo primeiro mekrareremex. A palha, matéria-prima utilizada na construção do artefato, nesse período ainda está verde, seu estado natural.

Quando a palha já está quase seca, o bô é deixado na casa do segundo mekrareremex e este tem a função de dar a volta no meio da aldeia. Passam-se alguns dias e o bô é deixado na casa do terceiro mekrareremex. Este ritual marca a terceira etapa em que os guerreiros vão para o mato a pedido do terceiro mekrareremex.

A comida a ser levada para o mato (bà $\mathrm{kam}$ ) é providenciada pelo dono da festa. Eles levam kwyrydjwynh (macaxeira), tyryti (banana), môp (uma espécie de inhame roxo), beró ngrà, jàt (batata) e outros mantimentos oriundos da própria comunidade. Depois de tudo preparado vão para a caçada (mry ijabej mokraj) e começam a procurar as carnes para a grande cerimônia.

No acampamento, o dono da festa fica preparando a comida ou omrõ na língua Mẽbêngôkre, enquanto os caçadores vão buscar os bichos como porcão (angrô), anta (kukryt) e principalmente o jabuti (kaprãn) a caça mais esperada, por ser um alimento tradicional servido ao final da cerimônia. Quando os homens voltam do mato é tarefa dos mekrareremex servir o omrõ, a fim de que

\footnotetext{
5 Comida típica dos Mẽbêngôkre, na qual utiliza - se carne (mry) e mandioca (kwyrydjwynh), são assados em fogo especial feito por mulheres, com uma camada de lenha e uma camada de pedra. Após a queima da lenha o berarubu que está envolto de palha de banana é colocado em cima das pedras quentes e abafado com mais folhas e uma lona. Passamse algumas horas e a comida está pronta;

6 Enfeite que se assemelha a uma fantasia feita com palha de buriti que é usado somente pelo homem, (o mekrareremex), nessa cerimônia.
} 
todos possam se saciar e descansar para encarar uma nova busca no dia seguinte.

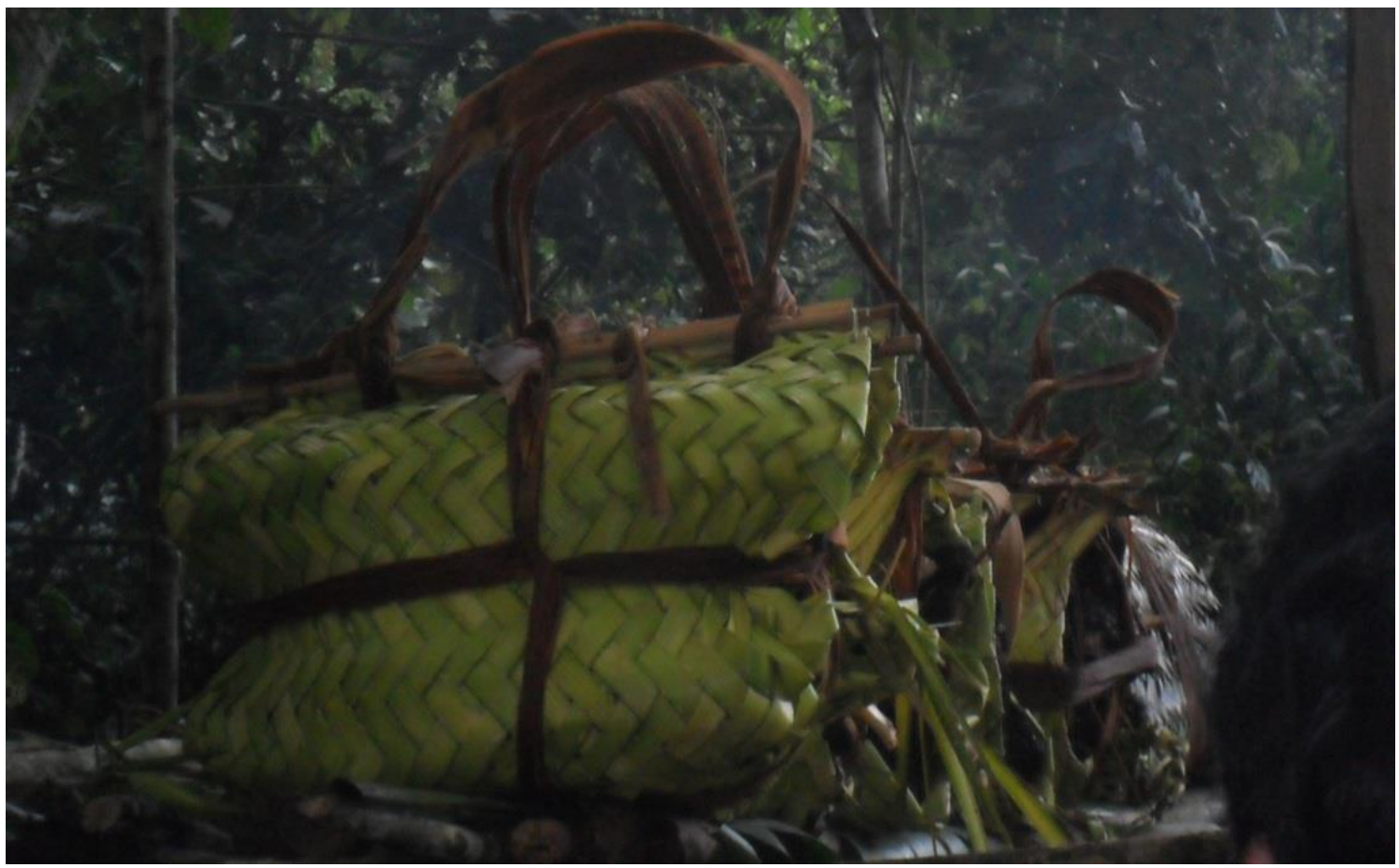

Figura 2 - A caça de Mry para a festa das mulheres em Kikretum, 2013. (Fonte: arquivo pessoal).

Quando já têm carnes suficiente, o "dono da festa" se pinta com mrôti, (tinta feita da semente do jenipapo utilizada nas pinturas Mẽbêngôkre) juntamente com os outros homens. Eles voltam para casa dando início ao ijôtyry ãm to, simbolizando um marcador de tempo cerimonial após a caçada.

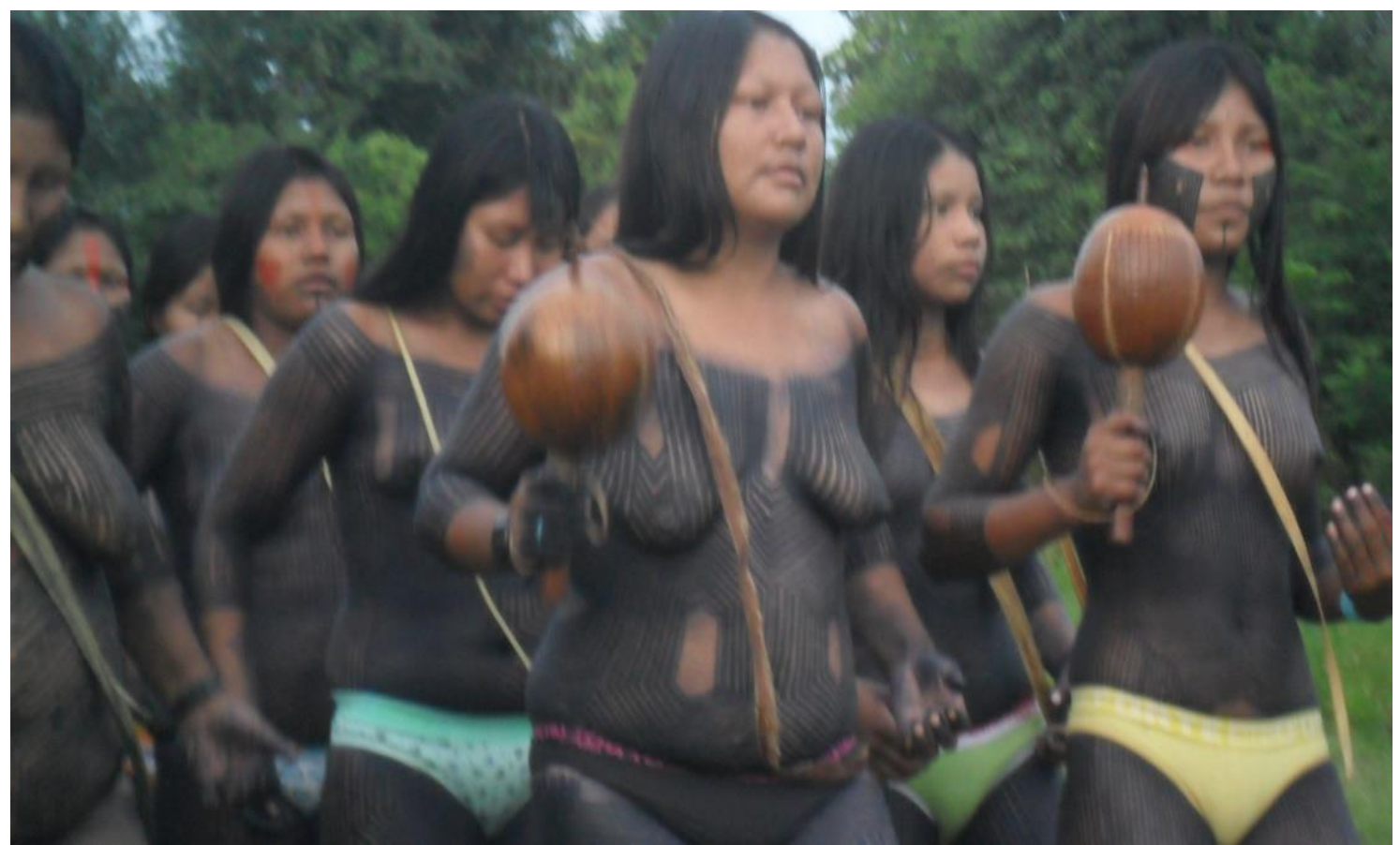


Após término da fase acima citada, inicia-se o jôk kre jaka ãn to, que também marca a passagem temporal. Nesse período as mulheres raspam o cabelo e se pintam, marcando a segunda etapa após a caçada. Finalmente após esse acontecimento, surge a fase mais formal e talvez mais esperada por muitos, a metoro raj, grande dança ou cerimônia maior. Encaminhando-se para o final.

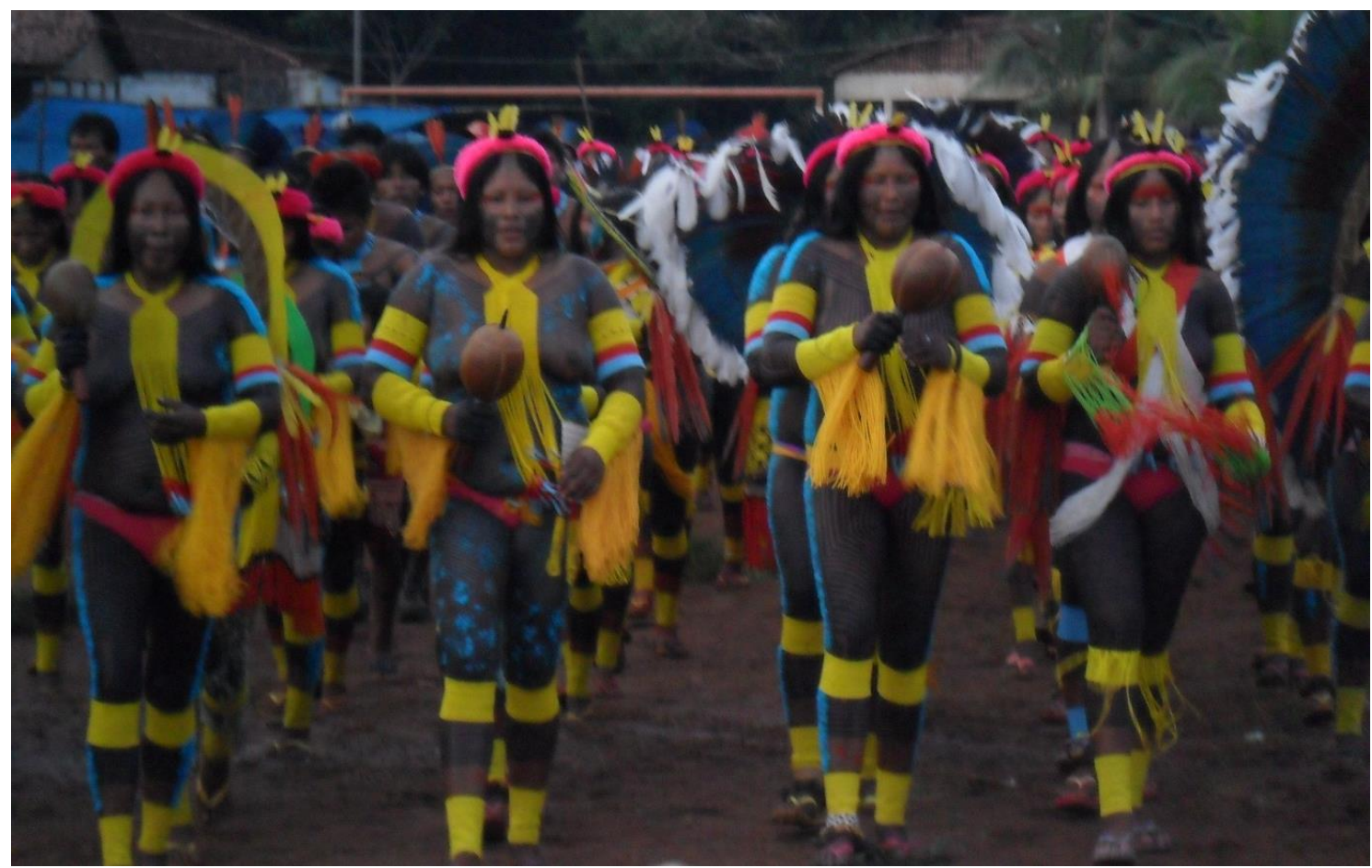

Figura 4 - Mulheres Mẽbêngôkre dançando enfeitadas na grande dança ao final da cerimônia Menire Bij’ôk. Aldeia Kikretum, 2013. (Foto: arquivo pessoal).

Ao final dessa cerimônia os pais cujos filhos vão receber nomes, vão para casa e arrumam o chão com folhas de kamêrêkàk (açaí) ou como acontece com mais frequência atualmente, colocam um plástico no chão e as crianças se sentam. O responsável para dar nomes que geralmente é alguém que tenha um parentesco próximo, chega para dar nomes. 


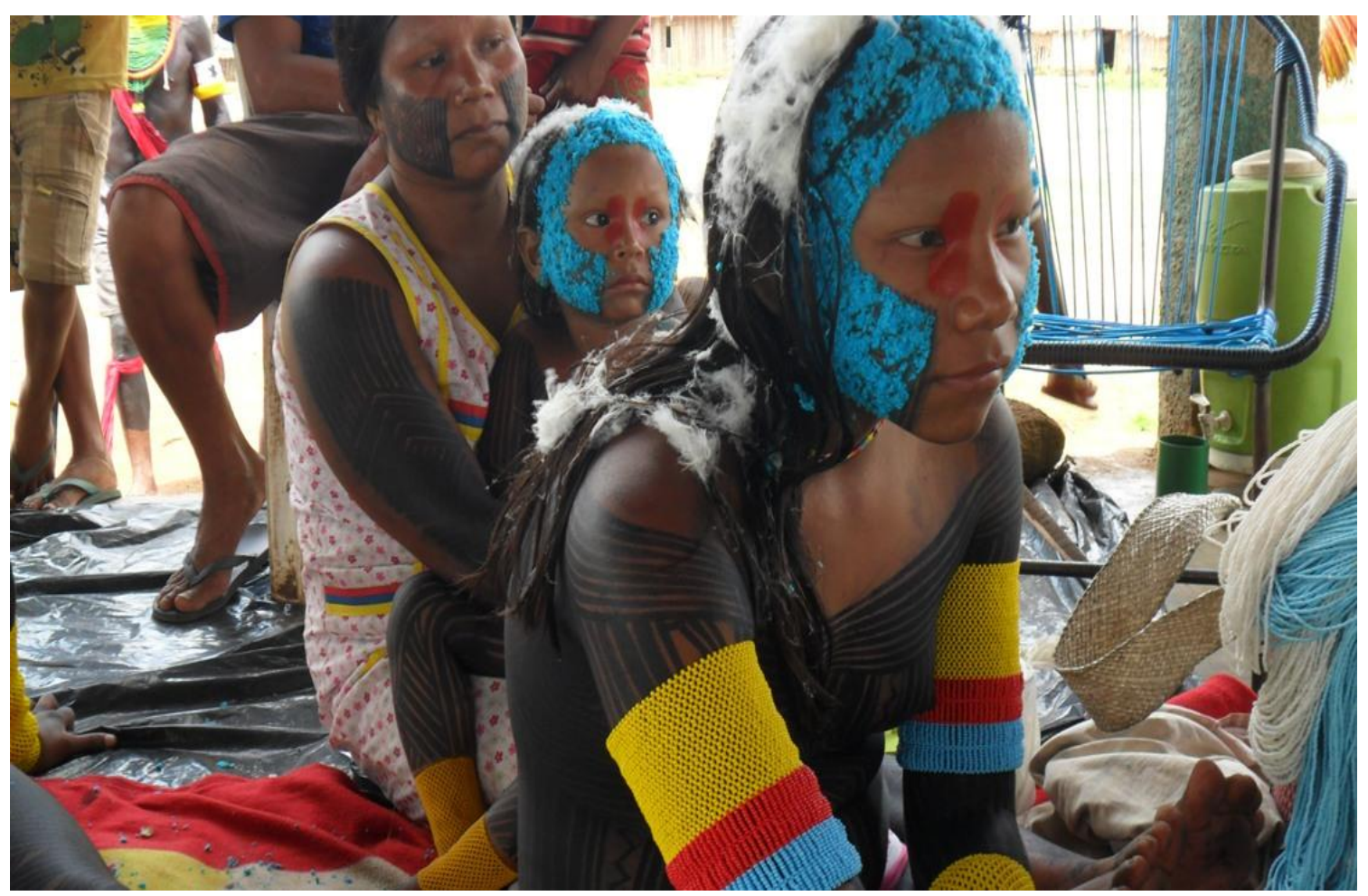

Figura 5 - Crianças no ritual de nominação. Aldeia Kikretum, 2013. (Foto: arquivo pessoal).

Nessa ocasião de nominação, uma criança pode receber mais de um nome, sendo que a partir dali ela comumente atenderá por todos eles. Tal ritual sinaliza que a cerimônia terminou. Mas, como observa André Demarchi (2015:25), "As festas, na verdade, não têm exatamente nem começo nem fim; de certa forma, elas são um aquecimento das condições do ritual que estão sempre ali como um fogo baixo alimentado com lenha dura”.

\section{Algumas Considerações}

Nesse sentido, pode dizer que a compreensão da complexidade que envolve as cerimônias Mẽbêngôkre é uma tarefa árdua que exige um trabalho minucioso de observação e pesquisa de campo. Ainda assim, não há detalhes que escapam aos olhos.

Devido a poucos registros documentais da história desse povo, tendo em vista a tradição oral, e esse universo cosmológico diferenciado e instigante, torna-se um campo fértil pela qual o pesquisador possui inúmeras situações de investigação, que nos ajuda a compreender e respeitar seus modos de vida, e ao mesmo tempo nos ensina a lidar com nossos próprios. 


\section{Referências}

CARNEIRO DA CUNHA, M. Cultura com aspas e outros ensaios. São Paulo: Ubu Editora, 2017, $432 \mathrm{pp}$.

DEMARCHI, A. Metoro Kukràdjà: ensaio fotoetnográfico sobre a estética ritual Mebengôkre - Kayapó. Rio de Janeiro: Museu do Índio, 2015.

DEMARCHI, A. Kayapó: An'gá Mejxtire, A miçanga é bonita: uma etnografia dos artefatos em transformação. In: No caminho da miçanga: um mundo que se faz de contas. (Org. Els Lagrou). Rio de Janeiro: Museu do Índio, 2016.

LEA, V. Gênero Feminino Mebengokre (Kayapó): desvelando representações desgastadas. Cadernos Pagu (3),1994: pp. 85-115.

LEA, V. R. Riquezas Intangíveis de Pessoas Partíveis: Os Mebêngôkre (Kayapó) do Brasil Central. São Paulo: Edusp, Fapesp. 2012.

SAHLINS, M. O "pessimismo Sentimental" e a Experiência Etnográfica - Parte I, Mana, v. 3, n.1, 1997, pp. 41-73.

TURNER, T. Da Cosmologia à História: resistência, adaptação e consciência social entre os Kayapó. Cadernos de Campo $n^{\circ} 1-1991$. São Paulo, Periódicos.usp.br. 2014. Tradução: David Soares. 